\title{
Improving flexural ductility of high-strength concrete beams
}

\author{
A. K. H. Kwan PhD, CEng, MICE, S. L. Chau MPhil and F. T. K. Au PhD, CEng, MICE, FIStructE
}

With the advent of advanced mineral and chemical admixtures, the strength level of concrete has been raised dramatically and high-strength concrete (HSC) is becoming more and more commonly used. However, HSC is generally more brittle than normal strength concrete. In fact, it has been shown that the use of HSC, if not properly controlled, could significantly reduce the flexural ductility of reinforced concrete beams. Herein, it is proposed to compensate for the reduction in flexural ductility owing to the use of HSC by adding compression and confining reinforcements. A parametric study based on complete moment-curvature analysis of beam sections made of different grades of concrete and provided with different amounts of tension, compression and confining reinforcements has been carried out to evaluate the increases in flexural ductility achievable by adding compression and confining reinforcements. From the numerical results, the compression and/or confining reinforcements needed to maintain a consistent level of minimum flexural ductility at all concrete strength levels have been determined and correlated to the concrete strength for direct evaluation in the design of HSC beams.

\section{NOTATION}

$A_{\mathrm{sc}} \quad$ area of compression steel reinforcement

$A_{\text {st }} \quad$ area of tension steel reinforcement

$b$ breadth of beam section

c width of unconfined zone

$d \quad$ effective depth of beam section

$E_{\mathrm{s}} \quad$ elastic modulus of steel reinforcement

$\boldsymbol{f}_{\mathrm{c}} \quad$ in situ uniaxial compressive strength of concrete

$\boldsymbol{f}_{\mathrm{r}} \quad$ confining stress

$\boldsymbol{f}_{\mathrm{yc}} \quad$ yield strength of compression steel reinforcement

$\boldsymbol{f}_{\mathrm{yt}} \quad$ yield strength of tension steel reinforcement

$h$ total depth of beam section

$\mu \quad$ curvature ductility factor

$\rho_{\mathrm{b}} \quad$ balanced steel ratio

$\rho_{\mathrm{c}} \quad$ compression steel ratio $\left(\rho_{\mathrm{c}}=A_{\mathrm{sc}} / b d\right)$

$\rho_{\mathrm{t}} \quad$ tension steel ratio $\left(\rho_{\mathrm{t}}=A_{\mathrm{st}} / b d\right)$

$\phi_{\mathrm{u}} \quad$ ultimate curvature of beam section

$\phi_{\mathrm{y}} \quad$ yield curvature of beam section

\section{INTRODUCTION}

The strength level of concrete has been raised dramatically over the past two decades owing to the advent of ultra-fine mineral admixtures, such as condensed silica fume, and the development of highly effective chemical admixtures such as third-generation superplasticisers. This, together with the everincreasing height of buildings and span length of bridges, which demand higher-strength materials, high-strength concrete (HSC) is gaining popularity in the construction industry. However, since HSC tends to fail quite explosively, its use in reinforced concrete $(\mathrm{RC})$ structures may result in brittle failure, ${ }^{1}$ which engineers need to guard against. Unfortunately, the existing codes of practice provide little guidance for the ductility design of RC members cast of HSC.

There have been few theoretical studies on the flexural ductility of RC members cast of HSC. ${ }^{2-4}$ This is partly because HSC is still relatively new and partly because there is no simple method for direct evaluation of the flexural ductility of RC members. To evaluate the flexural ductility of an RC beam or column section cast of HSC, it is necessary to conduct a complete moment-curvature analysis extended well into the post-peak range using the actual stress-strain curves of the constitutive materials. Moreover, since at the post-peak stage, strain increment reversal occurs in the tension reinforcement even though the curvature is increasing monotonically, the stress-path dependence of the stress-strain relation of the steel reinforcing bars has to be considered in the analysis. ${ }^{5,6}$

In 2001, the current authors' research team developed a theoretical method for complete moment-curvature analysis of reinforced concrete beam sections that uses the actual stressstrain curves of the materials and takes into account the stresspath dependence of the constitutive relations. ${ }^{5,6}$ Since then, using the theoretical method, they have conducted several series of parametric studies on the effects of various structural parameters, including the concrete grade, steel yield strength and steel ratios, on the flexural ductility of beam sections. ${ }^{7,8}$ It was found that at a given tension steel ratio, the flexural ductility increases with the concrete grade but at the same tension steel to balanced steel ratio (i.e. at the same degree of under- or over-reinforcement), the flexural ductility decreases with the concrete grade. Hence, if reinforced to the same degree of under/over-reinforcement, an RC beam cast of HSC would have a significantly lower flexural ductility than that of a similar beam cast of normal concrete.

To ensure the provision of a certain minimum level of flexural 
ductility, most existing codes of practice set a maximum limit to the tension steel ratio either directly or indirectly. For instance, the 1999 version of ACI $318^{9}$ imposes a direct limit on the tension steel ratio at not more than 0.75 of the balanced steel ratio while the 2002 version of ACI $318^{10}$ imposes an indirect limit on the tension steel ratio by requiring the net tensile strain in the tension reinforcement to be not less than $0 \cdot 004$ when the concrete fails. On the other hand, BS $8110^{11}$ restricts the tension steel ratio by limiting the neutral axis depth to smaller than or equal to $0 \cdot 5$ of the effective depth. Likewise, NZS $3101^{12}$ restricts the tension steel ratio by limiting the neutral axis depth to no greater than $0 \cdot 75$ of the neutral axis depth of the balanced section. These limits are for all concrete regardless of concrete grade. In contrast, Eurocode $2^{13}$ restricts the tension steel ratio by limiting the neutral axis depth to no greater than 0.45 of the effective depth for concrete with cube strength lower than $50 \mathrm{MPa}$ and to no greater than 0.35 of the effective depth for concrete with cube strength equal to or higher than $50 \mathrm{MPa}$.

In a recent study on the provision of minimum flexural ductility to HSC beams, ${ }^{14}$ it was found that the existing limits specified in the above codes do not provide a consistent level of minimum flexural ductility and that to ensure a consistent level of minimum flexural ductility, both the tension to balanced steel ratio (i.e. the tension steel to balanced steel ratio) and the neutral axis to effective depth ratio (i.e. the neutral axis depth to effective depth ratio) have to be reduced as the concrete strength increases. The allowable tension to balanced steel and neutral axis to effective depth ratios that would provide a consistent level of minimum flexural ductility have been worked out and presented by Ho et al. ${ }^{14}$ Reducing these ratios would, however, limit the flexural strength potential that could be developed. It would be desirable for the same tension to balanced steel ratio or neutral axis to effective depth ratio to be applied to HSC beams regardless of the concrete grade.

Herein, an alternative method of compensating for the reduction in flexural ductility owing to the use of HSC by adding compression reinforcement, confining reinforcement, or both compression and confining reinforcements so that the same allowable tension to balanced steel ratio or neutral axis to effective depth ratio may be applied to HSC beams is proposed. In previous experimental studies $2,3,15,16$ and theoretical studies by the current authors' research team, ${ }^{5,17}$ the addition of compression and confining reinforcements has been found to be effective in improving the flexural ductility of HSC beams. The aim of the present study is to determine the compression and/or confining reinforcements needed to maintain the same level of minimum flexural ductility that has been provided in the past to normal-strength concrete beams while applying the same allowable tension to balanced steel ratio or neutral axis to effective depth ratio as before to HSC beams. The results are particularly useful for the design of heavily reinforced HSC beams.

\section{MOMENT-CURVATURE ANALYSIS AND FLEXURAL DUCTILITY}

The method of analysis employed herein has been presented earlier. ${ }^{5,6}$ Unlike other methods, the actual stress-strain curves of the constitutive materials are used for the analysis. In particular, the change in shape of the stress-strain curve of the concrete with the concrete grade and the dependence of the stress-strain relation of the steel reinforcement on the stresspath (i.e. the direction of strain increment) are considered. The stress-strain curves of the concrete are derived from the stress-strain curve model developed by Attard and Setunge ${ }^{18}$ and Attard and Stewart, ${ }^{19}$ which has been shown to be applicable to concrete with compressive strength ranging from 20 to $130 \mathrm{MPa}$. On the other hand, the stress-strain relation of the steel reinforcement is assumed to be linearly elasticperfectly plastic with strain hardening ignored. To cater for stress-path dependence, the unloading path is taken to follow the slope of the initial elastic portion of the stress-strain curve. Strain hardening could be incorporated if so wished but has been ignored herein because a recent study ${ }^{20}$ revealed that the effects of strain hardening are in general negligibly small except when the tension steel ratio is very low, in which case the flexural ductility is relatively large and is of no concern.

It is also assumed in the analysis that the compression reinforcement would not buckle even when the ultimate state has been reached and the resisting moment has dropped to half of the peak value. The tendency of the compression reinforcement to buckle is dependent not only on the bar diameter of the compression reinforcement but also on the spacing of the stirrups restraining the compression reinforcement from buckling. To ensure effectiveness of the compression reinforcement, closely spaced stirrups must be provided to prevent bucking of the compression reinforcement.

Figure 1 shows a typical beam section to be analysed. The moment-curvature behaviour of the beam section is analysed by applying prescribed curvature to the section incrementally starting from zero. At a given curvature, the bending strains developed are evaluated based on an assumed neutral axis depth. The corresponding stresses developed in the concrete and the steel reinforcement are then determined from their respective stress-strain curves, with the effects of confinement on the concrete within the confined zone and the stress-path

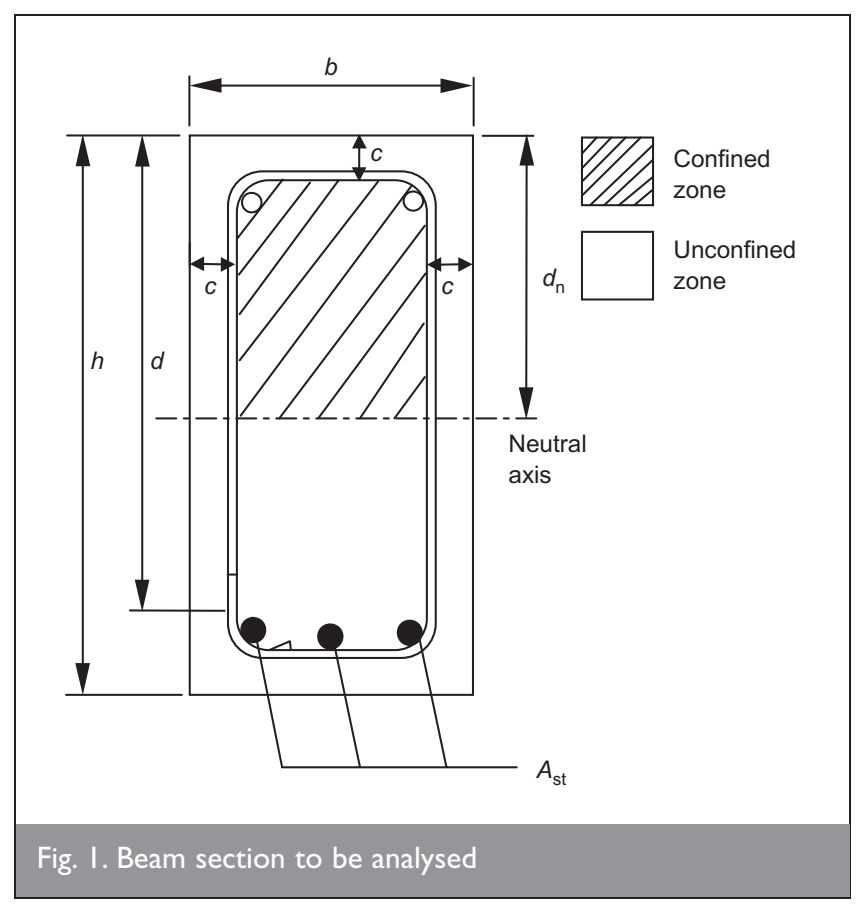


dependence of the stress-strain relation of the steel reinforcement taken into account. Axial equilibrium is then checked and the neutral axis depth adjusted to satisfy the axial equilibrium condition. Finally, the resisting moment is evaluated from the moment equilibrium condition. The above procedure is repeated until the curvature is large enough for the resisting moment to reach a peak value and then drop by more than $50 \%$.

A parametric study on the flexural ductility of beam sections provided with compression and/or confining reinforcements has been carried out. The beam sections analysed, shown in Fig. 1, have constant dimensions of $b=300 \mathrm{~mm}, h=600 \mathrm{~mm}$ and $d=550 \mathrm{~mm}$. An unconfined zone having a width of $c=40 \mathrm{~mm}$ is incorporated to cater for the practical situation that not all the concrete in the compression zone can be confined. To cover both normal- and high-strength concrete, the concrete compressive strength $\boldsymbol{f}_{\mathrm{c}}$ is varied from 30 to $90 \mathrm{MPa}$. For the steel reinforcement, the steel is assumed to have a constant elastic modulus of $E_{\mathrm{s}}=200 \mathrm{GPa}$ and constant yield strengths of $\boldsymbol{f}_{\mathrm{yc}}=\boldsymbol{f}_{\mathrm{yt}}=460 \mathrm{MPa}$. To study the variation of flexural ductility with the degree of under/over-reinforcement, the tension steel ratio $\rho_{\mathrm{t}}\left(\rho_{\mathrm{t}}=A_{\mathrm{st}} / b d\right)$ is varied from 0.2 to $1 \cdot 2$ times the balanced steel ratio. In order to evaluate the effects of compression and confining reinforcements, the compression steel ratio $\rho_{\mathrm{c}}\left(\rho_{\mathrm{c}}=A_{\mathrm{sc}} / b d\right)$ provided is varied from 0 to $2.5 \%$ while the confining stress $\boldsymbol{f}_{\mathrm{r}}$ applied is varied from 0 to $3 \mathrm{MPa}$. The confining stress $\boldsymbol{f}_{\mathbf{r}}$ is dependent on the confining reinforcement and may be evaluated using the method proposed by Mander et al. ${ }^{21}$ Typical values of $\boldsymbol{f}_{\mathrm{r}}$ for beam sections with different configurations and amounts of confining reinforcement provided are illustrated in Fig. 2. The confining reinforcement provided is not expressed in terms of any steel area or ratio because its effect is dependent not only on the steel area but also on the configuration and is in general better measured in terms of the confining stress that could be developed.

Some typical moment-curvature curves of the beam sections showing the effects of compression and confining reinforcements are presented in Figs 3 and 4, respectively. From Fig. 3, it can be seen that for under-reinforced sections, the addition of compression reinforcement would enhance the moment capacity only slightly but would increase the flexural ductility quite substantially, while for over-reinforced sections, the addition of compression reinforcement would significantly increase both the moment capacity and flexural ductility. Likewise, from Fig. 4, it can be seen that for under-reinforced sections, the addition of confining reinforcement would enhance the moment capacity only marginally but would increase the flexural ductility substantially, while for overreinforced sections, the addition of confining reinforcement would significantly increase both the moment capacity and flexural ductility. In any case, regardless of whether the beam section is under-reinforced or over-reinforced, the provision of either compression or confining reinforcement could significantly improve the flexural ductility of the beam section.

The effects of compression reinforcement may be explained as follows. With compression reinforcement added, the internal compressive force is shared between the concrete and the compression steel. As a result, the neutral axis is drawn towards the compression side and away from the tension steel, leading to a smaller neutral axis depth and a larger tensile strain induced in the tension steel. If the section is under-reinforced, the larger tensile strain induced would cause earlier yielding of the tension steel but this would have little effect on the moment capacity because the moment capacity is in such case governed mainly by the yield stress of the tension steel. If the section is over-reinforced, the larger tensile strain induced would cause a larger tensile stress to be developed in the tension steel and therefore the moment capacity would increase. Finally, regardless of whether the section is underor over-reinforced, the smaller neutral axis depth would for the same ultimate concrete strain increase the ultimate curvature and hence the flexural ductility of the section.

The effects of confining reinforcement may be explained as follows. With confining reinforcement added, both the compressive strength and compressive strain capacity of the 


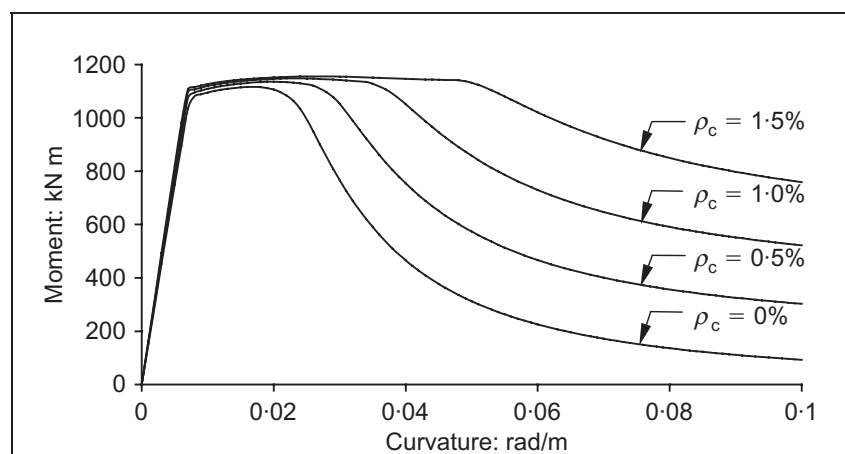

(a)

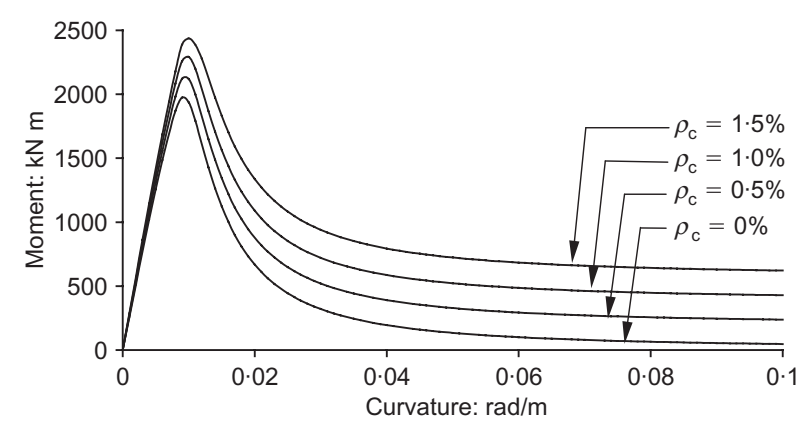

(b)

Fig. 3. Moment-curvature curves of sections with compression reinforcement: (a) under-reinforced sections with $f_{\mathrm{c}}=70 \mathrm{MPa}$ and $\rho_{\mathrm{t}}=0.5$ of balanced steel ratio at $\rho_{\mathrm{c}}=0 \%$; (b) over-reinforced sections with $f_{\mathrm{c}}=70 \mathrm{MPa}$ and $\rho_{\mathrm{t}}=1.2$ of balanced steel ratio at $\rho_{\mathrm{c}}=0 \%$

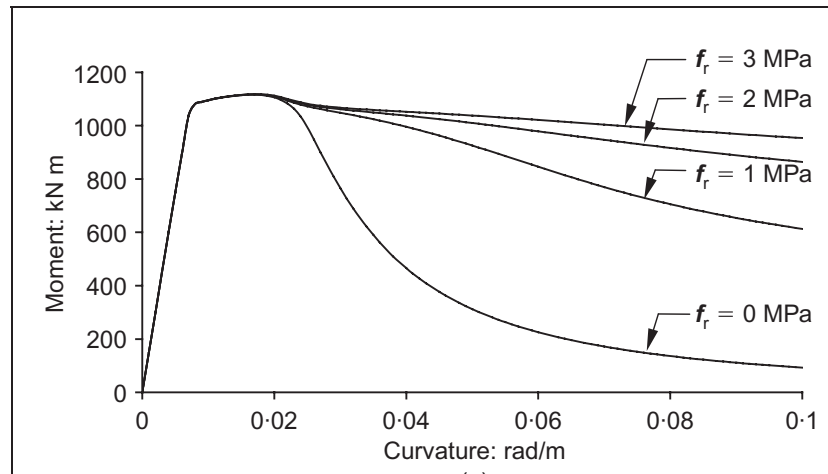

(a)

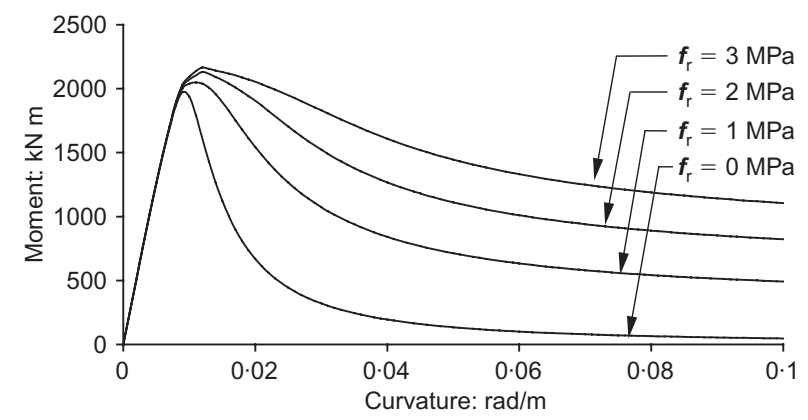

(b)

Fig. 4. Moment-curvature curves of sections with confining reinforcement: (a) under-reinforced sections with $f_{\mathrm{c}}=70 \mathrm{MPa}$ and $\rho_{\mathrm{t}}=0.5$ of balanced steel ratio at $\boldsymbol{f}_{\mathrm{r}}=0 \%$; (b) over-reinforced sections with $f_{\mathrm{c}}=70 \mathrm{MPa}$ and $\rho_{\mathrm{t}}=1 \cdot 2$ of balanced steel ratio at $f_{r}=0 \%$ concrete would increase. The higher compressive strength would lead to a smaller neutral axis depth and a larger tensile strain induced in the tension steel, while the larger compressive strain capacity would lead to a larger ultimate concrete strain. If the section is under-reinforced, the larger tensile strain induced would cause earlier yielding of the tension steel but this would have little effect on the moment capacity because the moment capacity is in such case governed mainly by the yield stress of the tension steel. If the section is overreinforced, the larger tensile strain induced would cause a larger tensile stress to be developed in the tension steel and therefore the moment capacity would increase. Finally, regardless of whether the section is under- or over-reinforced, the smaller neutral axis depth and larger ultimate concrete strain would together dramatically increase the ultimate curvature and hence the flexural ductility of the section.

The provision of compression or confining reinforcement also alters the balanced steel ratio of the beam section. In the present study, the balanced steel ratio is evaluated by a trialand-error process of analysing beam sections with different tension steel ratios and checking in each beam section to ascertain whether the tension reinforcement has yielded during failure or not. The balanced steel ratios of beam sections with different concrete strength, different compression steel ratios and different levels of confinement are listed in Tables 1 and 2. It is evident that for a given concrete strength, the balanced steel ratio increases with both the amount of compression reinforcement added and the level of confinement provided.

From the moment-curvature curves, the flexural ductility of the beam sections analysed may be determined in terms of a curvature ductility factor $\mu$ defined as

$$
\text { I } \quad \mu=\phi_{\mathrm{u}} / \phi_{\mathrm{y}}
$$

where $\phi_{\mathrm{u}}$ and $\phi_{\mathrm{y}}$ are the ultimate curvature and yield curvature, respectively. The ultimate curvature is the curvature at which the resisting moment has, after reaching the peak, dropped to $80 \%$ of the peak moment, while the yield curvature is taken as the curvature at the hypothetical yield point of an equivalent linearly elastic-perfectly plastic system with an elastic stiffness equal to the secant stiffness of the beam section at $75 \%$ of the peak moment and a yield moment equal to the peak moment.

The curvature ductility factors so derived from the above equation for sections with compression or confining reinforcement provided are depicted in Figs 5 and 6, respectively, where the curvature ductility factor $\mu$ is plotted against the tension steel ratio $\rho_{\mathrm{t}}$ at different concrete strength $\boldsymbol{f}_{\mathrm{c}}$. From these results, it can be seen that the ductility factor $\mu$ decreases as the tension steel ratio $\rho_{\mathrm{t}}$ increases. Nevertheless, at a fixed tension steel ratio $\rho_{\mathrm{t}}$, the ductility factor $\mu$ increases as the compression steel ratio $\rho_{\mathrm{c}}$ or the confining stress $\boldsymbol{f}_{\mathrm{r}}$ increases, showing that the addition of compression or confining reinforcement can effectively improve the flexural ductility. Hence, the incorporation of compression and/or confining reinforcements may help to restore the flexural ductility of HSC beams to a certain minimum level.

The minimum level of flexural ductility that has been provided 


\begin{tabular}{|lcccc|}
\hline & \multicolumn{5}{c|}{ Balanced steel ratio, $\rho_{\mathrm{b}}: \%$} \\
\cline { 2 - 4 } $\boldsymbol{f}_{\mathrm{c}}: \mathrm{MPa}$ & $\rho_{\mathrm{c}}=0 \%$ & $\rho_{\mathrm{c}}=0.5 \%$ & $\rho_{\mathrm{c}}=1.0 \%$ & $\rho_{\mathrm{c}}=1.5 \%$ \\
\hline 30 & 3.18 & 3.68 & 4.18 & 4.68 \\
50 & 4.66 & $5 \cdot 16$ & 5.66 & 6.16 \\
70 & 6.02 & 6.52 & 7.02 & 7.52 \\
90 & 7.24 & 7.74 & 8.24 & 8.74 \\
& & & & \\
\hline
\end{tabular}

\begin{tabular}{|c|c|c|c|c|}
\hline \multirow[b]{2}{*}{$f_{\mathrm{c}}: \mathrm{MPa}$} & \multicolumn{4}{|c|}{ Balanced steel ratio, $\rho_{\mathrm{b}}: \%$} \\
\hline & $\boldsymbol{f}_{\mathrm{r}}=0 \mathrm{MPa}$ & $\boldsymbol{f}_{\mathrm{r}}=\mathrm{I} \mathrm{MPa}$ & $\boldsymbol{f}_{\mathrm{r}}=2 \mathrm{MPa}$ & $\boldsymbol{f}_{\mathrm{r}}=3 \mathrm{MPa}$ \\
\hline 30 & $3 \cdot 18$ & 4.19 & 4.93 & $5 \cdot 62$ \\
\hline 50 & 4.66 & 5.80 & 6.63 & $7 \cdot 42$ \\
\hline 70 & 6.02 & $7 \cdot 19$ & 8.06 & 8.90 \\
\hline 90 & $7 \cdot 24$ & 8.42 & $9 \cdot 31$ & 10.16 \\
\hline
\end{tabular}

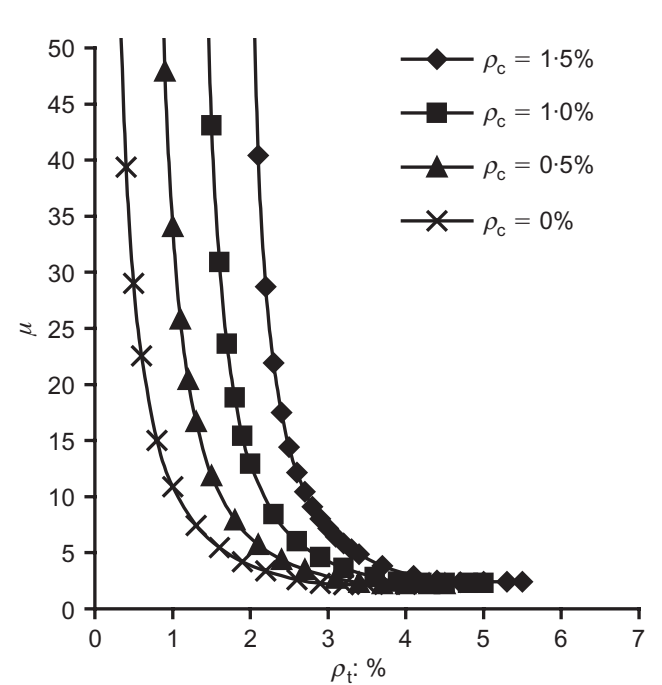

(a)

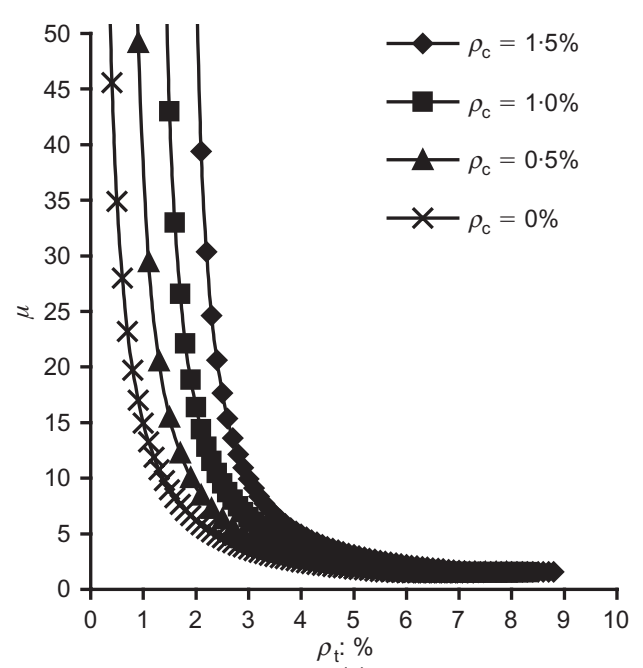

(c)

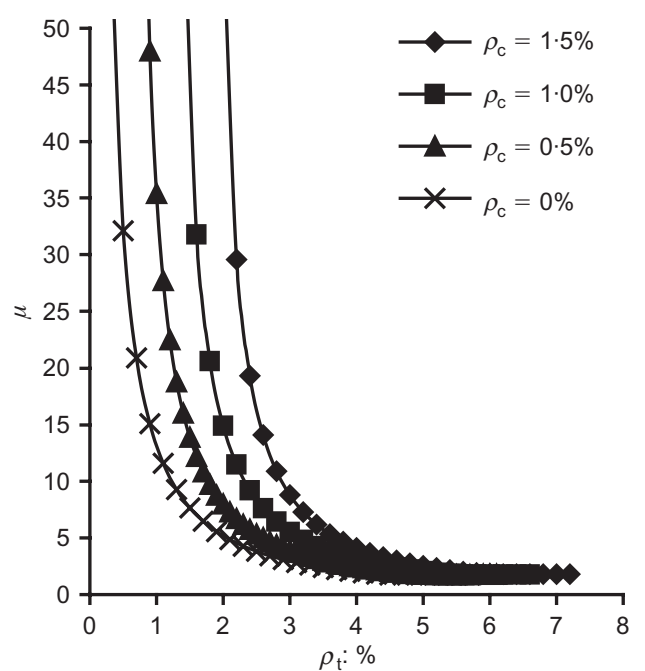

(b)

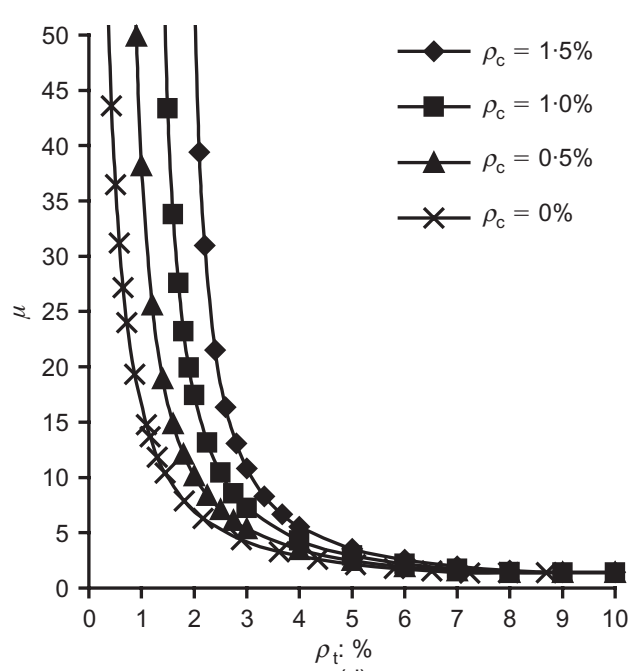

(d) 


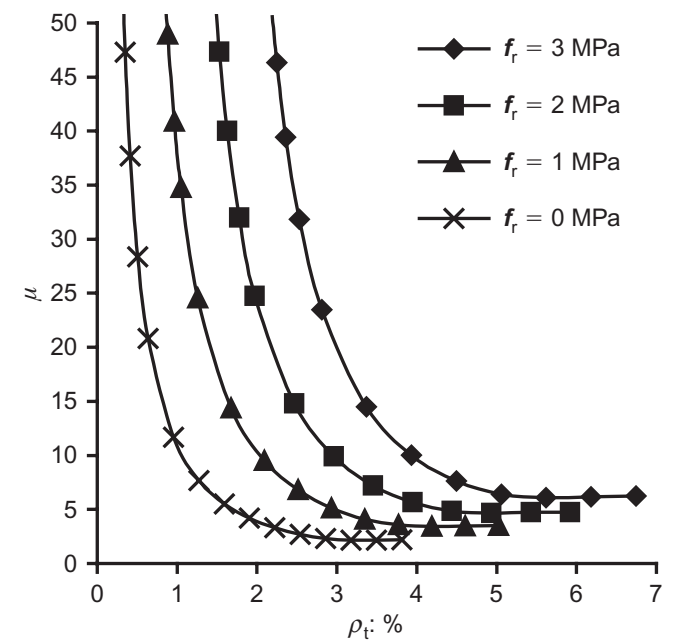

(a)

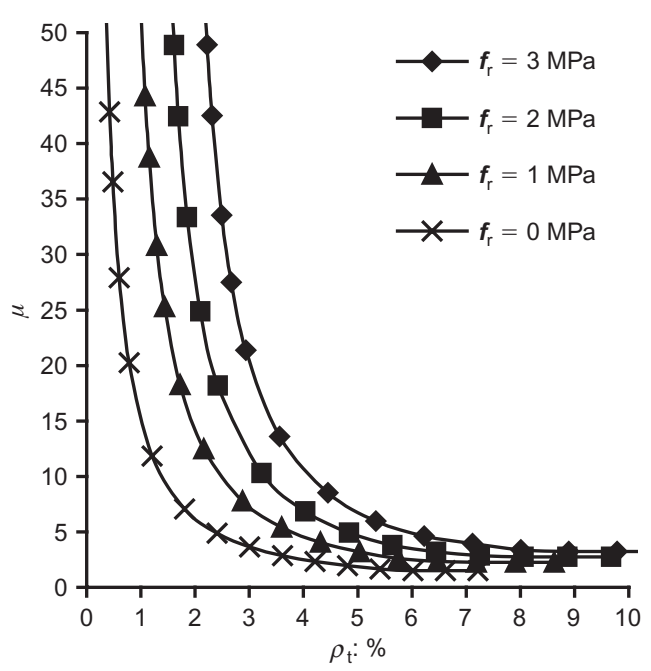

(c)

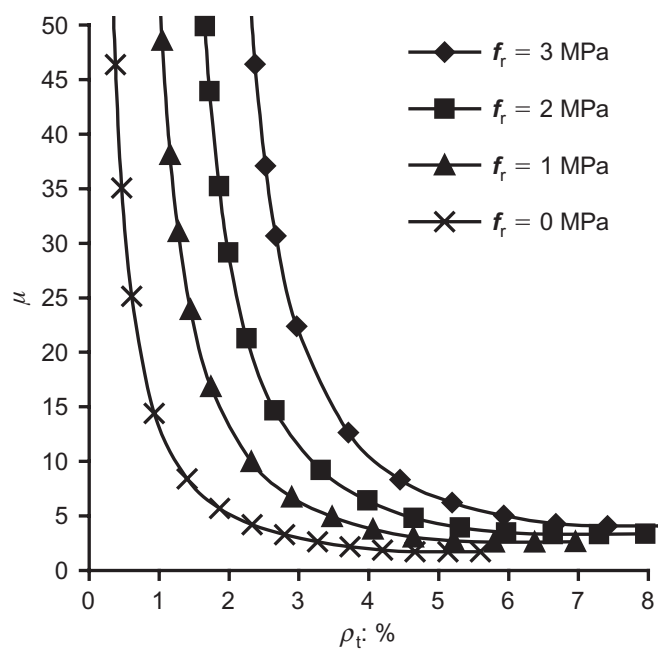

(b)

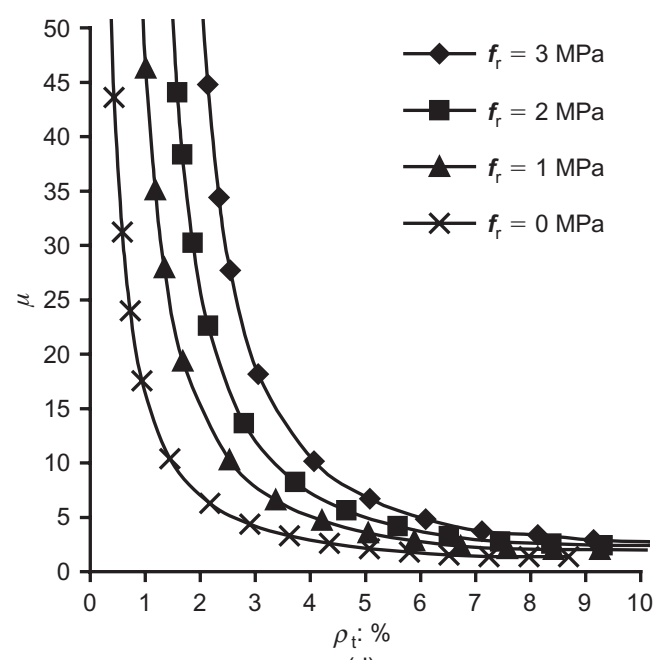

(d)

Fig. 6. Ductility factors of sections with confining reinforcement: (a) $f_{c}=30 \mathrm{MPa}$; (b) $f_{c}=50 \mathrm{MPa}$; (c) $f_{c}=70 \mathrm{MPa}$; (d) $f_{\mathrm{c}}=90 \mathrm{MPa}$

in the past to normal-strength concrete beams may be evaluated by assuming a concrete strength $\boldsymbol{f}_{\mathrm{c}}$ of $30 \mathrm{MPa}$. In ACI $318-99,{ }^{9}$ the tension to balanced steel ratio is limited to a maximum of $0 \cdot 75$. At a concrete strength $\boldsymbol{f}_{\mathrm{c}}$ of $30 \mathrm{MPa}$, this would provide a minimum ductility factor $\mu$ of $3 \cdot 32$. In BS $8110,{ }^{11}$ the neutral axis to effective depth ratio is limited to a maximum of $0 \cdot 5$. At a concrete strength $\boldsymbol{f}_{\mathrm{c}}$ of $30 \mathrm{MPa}$, this would provide a minimum ductility factor $\mu$ of $3 \cdot 22$. In order to maintain a consistent level of minimum flexural ductility, it is proposed to set a fixed minimum value of 3.32 or $3 \cdot 22$ for the ductility factor $\mu$.

\section{APPLYING A FIXED ALLOWABLE TENSION TO BALANCED STEEL RATIO}

It is proposed herein to maintain a minimum ductility factor of $\mu=3.32$ while applying a fixed allowable tension to balanced steel ratio of 0.75 to all concrete beam sections by adding compression reinforcement, confining reinforcement, or both compression and confining reinforcements. It should be noted that while applying a fixed tension to balanced steel ratio of $0 \cdot 75$, the balanced steel ratio is taken to be a function only of the concrete strength with the increase in balanced steel ratio owing to the addition of compression and/or confining reinforcements ignored.

If only compression reinforcement is to be added, the amounts needed at different concrete strength levels to achieve a ductility factor of $\mu=3.32$ have been determined by a trialand-error process of analysing the complete momentcurvature behaviour of beam sections with different compression steel ratios and finding the compression steel ratio corresponding to the specified ductility factor of $\mu=3 \cdot 32$. The compression steel ratio needed is found to increase with the concrete strength more or less as a linear function and may be correlated to the concrete strength for direct evaluation in the design of HSC beams by the following equation

\begin{tabular}{|l|l|}
\hline 2 & $3350 \rho_{\mathrm{c}}=\boldsymbol{f}_{\mathrm{c}}-30$ \\
\hline
\end{tabular}

in which $\boldsymbol{f}_{\mathrm{c}}$ is in MPa. Basically, the compression steel ratio $\rho_{\mathrm{c}}$ required to maintain the specified minimum level of flexural ductility is given by $\left(\boldsymbol{f}_{\mathrm{c}}-30\right) / 3350$. At a concrete strength of $\boldsymbol{f}_{\mathrm{c}}=30 \mathrm{MPa}$, no compression reinforcement is required and at 
concrete strengths of $\boldsymbol{f}_{\mathrm{c}}=50,70$ and $90 \mathrm{MPa}$, the compression steel ratios required are $0 \cdot 6,1 \cdot 2$ and $1 \cdot 8 \%$, respectively.

If only confining reinforcement is to be added, the amounts needed at different concrete strength levels to achieve a ductility factor of $\mu=3 \cdot 32$ have been determined by a similar trial-and-error process of analysing the complete momentcurvature behaviour of beam sections with different confining stresses applied and finding the confining stress corresponding to the specified ductility factor of $\mu=3 \cdot 32$. As before, the confining stress needed increases with the concrete strength approximately as a linear function and may be correlated to the concrete strength for direct evaluation by the following equation

\begin{tabular}{|l|l|}
\hline 3 & $54 \boldsymbol{f}_{\mathrm{r}}=\boldsymbol{f}_{\mathrm{c}}-30$ \\
\hline
\end{tabular}

in which both $\boldsymbol{f}_{\mathrm{r}}$ and $\boldsymbol{f}_{\mathrm{c}}$ are in MPa. Basically, the confining stress $\boldsymbol{f}_{\mathrm{r}}$ required to maintain the specified minimum level of flexural ductility is given by $\left(\boldsymbol{f}_{\mathrm{c}}-30\right) / 54$. At a concrete strength of $\boldsymbol{f}_{\mathrm{c}}=30 \mathrm{MPa}$, no confining reinforcement is required and at concrete strengths of $f_{\mathrm{c}}=50,70$ and $90 \mathrm{MPa}$, the confining stresses required are $0 \cdot 37,0 \cdot 74$ and $1 \cdot 11 \mathrm{MPa}$, respectively.

If both compression and confining reinforcements are to be added, then less compression reinforcement and less confining reinforcement than in the previous cases would be needed. There are many different possible combinations but it can be shown that since the effects of compression and confining reinforcements are additive, the combined amounts of compression and confining reinforcements needed may be evaluated using the following equation

$$
43350 \rho_{\mathrm{c}}+54 \boldsymbol{f}_{\mathrm{r}}=\boldsymbol{f}_{\mathrm{c}}-30
$$

Complete moment-curvature analysis confirmed that with compression and confining reinforcements so provided, the ductility factor of the beam section would not deviate from the specified minimum value of $\mu=3 \cdot 32$ by more than $\pm 5 \%$.

Using equation (4), the designer can have the flexibility of putting in more compression reinforcement and less confining reinforcement, or vice versa. The various combinations of compression and confining reinforcements that may be considered are tabulated in Table 3. There is no general rule as to when more compression reinforcement should be provided and when more confining reinforcement should be provided instead; this has to be considered on a case-by-case basis. For instance, when the addition of compression reinforcement could lead to steel congestion, then more confining and less compression reinforcement should be provided. On the other hand, when the addition of confining reinforcement is not practical as in the case of non-rectangular beams with thin flanges, then no confining reinforcement should be added and only compression reinforcement should be provided instead. If, from the reinforcement detailing point of view, both compression and confining reinforcements may be added, then a cost-benefit analysis should be carried out to determine the proportions of compression and confining reinforcements to be provided. The present authors have considered a number of typical cases and found that for solid rectangular beams the provision of more confining and less compression reinforcement is usually more economical. However, there could be exceptions and this observation should not be treated as a general rule.

Finally, it should be borne in mind that the compression reinforcement so provided to allow a fixed allowable tension to balanced steel ratio of 0.75 to be applied to HSC beams should be considered as contributing to the internal compressive force developed in the concrete. If the tension steel ratio is to be increased to higher than $0 \cdot 75$ of the balanced steel ratio so as to further increase the flexural capacity of the beam section, then extra compression steel has to be provided to balance that part of the tension steel above 0.75 of the balanced steel.

\section{APPLYING A FIXED ALLOWABLE NEUTRAL AXIS TO EFFECTIVE DEPTH RATIO}

If a fixed allowable neutral axis to effective depth ratio of 0.5 is to be applied and a minimum ductility factor of $\mu=3.22$ is to be maintained, the same strategy of adding compression reinforcement, confining reinforcement, or both compression and confining reinforcements may also be adopted. It should be noted at the outset, however, that applying a fixed neutral axis to effective depth ratio of 0.5 would not produce the same results as those produced by applying a fixed tension to balanced steel ratio of $0 \cdot 75$. At a fixed neutral axis to effective depth ratio of $0 \cdot 5$, the tension to balanced steel ratio would increase with the concrete strength and at a concrete strength $\boldsymbol{f}_{\mathrm{c}}$ greater than $30 \mathrm{MPa}$, the tension to balanced steel ratio would be higher than $\mathbf{0 \cdot 7 5}$. Hence, without compression or confining reinforcement, the application of a fixed neutral axis to effective depth ratio of 0.5 would lead to a lower flexural ductility and therefore to maintain a similar level of minimum flexural ductility, more compression and/or confining reinforcements would be needed.

Using the same trial-anderror process of analysing the complete moment-curvature behaviour of beam sections with different compression and/or confining reinforcements as before, the amounts of compression reinforcement needed if only compression reinforcement is 


\begin{tabular}{|lcccc|}
\hline \multicolumn{5}{c|}{ Compression steel ratio, $\rho_{\mathrm{c}}: \%$} \\
\cline { 2 - 5 } $\boldsymbol{f}_{\mathrm{c}}: \mathrm{MPa}$ & $\boldsymbol{f}_{r}=0 \mathrm{MPa}$ & $\boldsymbol{f}_{\mathrm{r}}=0.5 \mathrm{MPa}$ & $\boldsymbol{f}_{r}=1.0 \mathrm{MPa}$ & $\boldsymbol{f}_{r}=1.5 \mathrm{MPa}$ \\
\hline 30 & 0.0 & - & - & - \\
50 & 0.8 & 0.0 & - & - \\
70 & 1.6 & 0.8 & 0.0 & 0.0 \\
90 & 2.3 & 1.6 & 0.8 & \\
& & & \\
Table 4. Amounts of compression and confining reinforcement needed for applying a fixed \\
allowable neutral axis to effective depth ratio of 0.5 to all concrete
\end{tabular}

Through a trial-and-error numerical process, the amounts of compression and/ or confining reinforcements needed to maintain a minimum ductility factor of $\mu=3.32$ while applying a fixed allowable tension to balanced steel ratio of 0.75 regardless of the concrete grade have been determined and expressed in terms of the concrete strength in a single

to be added, the amounts of confining reinforcement needed if only confining reinforcement is to be added, and the combined amounts of compression and confining reinforcements needed if both are to be added to achieve a ductility factor of $\mu=3 \cdot 22$ at different concrete strength levels have been determined and correlated to the concrete strength to produce the following equations

\begin{tabular}{|l|l|}
\hline 5 & $2570 \rho_{\mathrm{c}}=\boldsymbol{f}_{\mathrm{c}}-30$ \\
\hline
\end{tabular}

\begin{tabular}{|l|l|}
\hline 6 & $39 \boldsymbol{f}_{\mathrm{r}}=\boldsymbol{f}_{\mathrm{c}}-30$ \\
\hline
\end{tabular}

\begin{tabular}{|l|l|}
\hline 7 & $2570 \rho_{\mathrm{c}}+39 \boldsymbol{f}_{\mathrm{r}}=\boldsymbol{f}_{\mathrm{c}}-30$ \\
\hline
\end{tabular}

Complete moment-curvature analysis confirmed that with compression and confining reinforcements so provided, the ductility factor of the beam section would not deviate from the specified minimum value of $\mu=3.22$ by more than $\pm 5 \%$. Using equation (7), the various combinations of compression and confining reinforcements that may be considered have been worked out and tabulated in Table 4 .

Comparing Table 4 with Table 3, it is evident that the amounts of compression and confining reinforcements needed to apply a fixed allowable neutral axis to effective depth ratio of 0.5 are larger than those needed to apply a fixed allowable tension to balanced steel ratio of $0 \cdot 75$, despite the slightly lower requirement of the minimum value of $\mu$. Relatively, it is easier to apply a fixed allowable tension to the balanced steel ratio.

\section{CONCLUSIONS}

The effects of adding compression and confining reinforcements on the flexural ductility of HSC beams have been evaluated by a parametric study of the complete moment-curvature behaviour of beam sections made of different grades of concrete and provided with different amounts of compression and confining reinforcements. Based on the numerical results, which prove that the addition of compression and/or confining reinforcements can effectively improve the flexural ductility, it is proposed to compensate for the reduction in flexural ductility owing to the use of HSC by adding compression and/or confining reinforcements so that a fixed allowable tension to balanced steel ratio or a fixed allowable neutral axis to effective depth ratio may be applied to all concrete beams regardless of the concrete grade. the flexibility of putting in more compression reinforcement and less confining reinforcement, or vice versa, depending on the situation and the relative cost-effectiveness of the two different types of reinforcement.

Through a similar trial-and-error process, the amounts of compression and/or confining reinforcements needed to maintain a minimum ductility factor of $\mu=3.22$ while applying a fixed allowable neutral axis to effective depth ratio of 0.5 regardless of the concrete grade have been determined and expressed in terms of the concrete strength in a single formula, equation (7). This formula also allows the designer to have the flexibility of deciding the relative proportions of compression and confining reinforcements to be provided. Since a constant neutral axis to effective depth ratio would lead to a tension to balanced steel ratio that increases with the concrete strength, the amounts of compression and confining reinforcements needed for applying a fixed allowable neutral axis to effective depth ratio are in general larger than those needed for applying a fixed allowable tension to balanced steel ratio.

\section{REFERENCES}

1. PAM H. J., KWAN A. K. H. and Islam M. S. Flexural strength and ductility of reinforced normal- and high-strength concrete beams. Proceedings of the Institution of Civil Engineers, Structures and Buildings, 2001, 146, No. 4, 381-389.

2. MAnsuR M. A., Chin M. S. and WeE T. H. Flexural behavior of high-strength concrete beams. ACI Structural Journal, 1997, 94, No. 6, 663-674.

3. Mendis P. A., Kovacic D. and Setunge S. Basis for the design of lateral reinforcement for high-strength concrete columns. Structural Engineering and Mechanics, 2000, 9, No. 6, 589-600.

4. Konstantinidis D. and KaPPOS A. J. Analytical modelling of confined HSC columns under flexure and axial load.

Magazine of Concrete Research, 2003, 55, No. 4, 395-403.

5. PAM H. J., KWAN A. K. H. and Ho J. C. M. Post-peak behavior and flexural ductility of doubly reinforced normal- and high-strength concrete beams. Structural Engineering and Mechanics, 2001, 12, No. 5, 459-474.

6. Ho J .C .M., KwAN A. K. H. and PAM H. J. Theoretical analysis of post-peak flexural behavior of normal- and high-strength concrete beams. Structural Design of Tall and Special Buildings, 2003, 12, No. 2, 109-125.

7. KWAN A. K. H., Ho J. C. M. and PAM H. J. Flexural strength and ductility of reinforced concrete beams. Proceedings of formula, equation (4). This formula allows the designer to have 
the Institution of Civil Engineers, Structures and Buildings, 2002, 152, No. 4, 361-369.

8. KWAN A. K. H., Ho J. C. M. and PAM H. J. Effects of concrete grade and steel yield strength on flexural ductility of reinforced concrete beams. Australian Journal of Structural Engineering, 2004, 5, No. 2, 119-138.

9. AMERICAN CONCRETE InSTITUTE. Building Code Requirements for Structural Concrete and Commentary. ACI, Farmington Hills, USA, 1999, ACI 318-99 and ACI 318R-99

10. AMERICAN CONCRETE InSTITUTE. Building Code Requirements for Structural Concrete and Commentary. ACI, Farmington Hills, USA, 2002, ACI 318-02 and ACI 318R-02

11. BRITISH STANDARDS InSTITUTION. Structural Use of Concrete, Code of Practice for Design and Construction. BSI, London, 1997, BS 8110.

12. STANDARDS NEW ZEALAND. Concrete Structures Standard: Part 1 - The Design of Concrete Structures. NZS, Wellington, New Zealand, 1995, NZS 3101.

13. Comité EuropéEn de Normalisation. Eurocode 2, Design of Concrete Structures-Part 1: General Rules and Rules for Buildings. CEN, Brussels, 1992.

14. Ho J. C. M., KwAN A. K. H. and PAM H. J. Minimum flexural ductility design of high-strength concrete beams. Magazine of Concrete Research, 2004, 56, No. 1, 13-22.
15. SHIN S. W., GHosh S. K. and Moreno J. Flexural ductility of ultra-high strength concrete members. ACI Structural Journal, 1989, 86, No. 4, 394-400.

16. Bernardo L. F. A. and Lopes S. M. R. Neutral axis depth versus flexural ductility in high-strength concrete beams. Journal of Structural Engineering, ASCE, 2004, 130, No. 3, 452-459.

17. Kwan A. K. H., Au F. T. K. and ChaU S. L. Theoretical study on effect of confinement on flexural ductility of normal and high-strength concrete beams. Magazine of Concrete Research, 2004, 56, No. 5, 299-309.

18. ATTARD M. M. and SETUNGE S. The stress-strain relationship of confined and unconfined concrete. ACI Materials Journal, 1996, 93, No. 5, 432-444.

19. ATtARD M. M. and SteWART M. G. A two parameter stress block for high-strength concrete. ACI Structural Journal, 1998, 95, No. 3, 305-317.

20. Ho J. C. M., AU F. T. K. and KWAN A. K. H. Effects of strain hardening of steel reinforcement on flexural strength and ductility of concrete beams. Structural Engineering and Mechanics, 2005, 19, No. 2, 185-198.

21. MANDER J. M., PRIESTLEY N. and PARK R. Theoretical stressstrain model for confined concrete. Journal of Structural Engineering ASCE, 1988, 114, No. 8, 1804-1826.

\section{What do you think?}

To comment on this paper, please email up to 500 words to the editor at journals@ice.org.uk

Proceedings journals rely entirely on contributions sent in by civil engineers and related professionals, academics and students. Papers should be 2000-5000 words long, with adequate illustrations and references. Please visit www.thomastelford.com/journals for author guidelines and further details. 